\title{
Partial tetrasomy of the proximal long arm of chromosome 15 in two patients: the significance of the gene dosage in terms of phenotype
}

\author{
Andras Szabo ${ }^{1,2}$, Marta Czako ${ }^{1,2}$, Kinga Hadzsiev ${ }^{1,2}$, Balazs Duga ${ }^{1,2}$, Katalin Komlosi $^{1,2}$ and Bela Melegh ${ }^{1,2^{*}}$
}

\begin{abstract}
Background: Large amounts of low copy number repeats in the 15q11.2q13.3 chromosomal region increase the possibility of misalignments and unequal crossover during meiosis in this region, leading to deletions, duplications, triplications and supernumerary chromosomes. Most of the reported cases with epilepsy, autism and Prader-Willi/ Angelman syndrome are in association with rearrangements of the proximal long arm of chromosome 15.

Results: Here we report the first two unrelated Hungarian patients with the same epileptic and dysmorphic features, who were investigated by array comparative genomic hybridization (array CGH). By G-banded karyotype followed by FISH and array CGH we could detect partial tetrasomy of the 15q11.2q13.3 chromosomal region, supporting proximal $15 q$ duplication syndrome. Findings of the array CGH gave fully explanation of the phenotypic features of these patients, including epileptic seizures, delayed development, hyperactivity and craniofacial dysmorphic signs. Besides the described features of isodicentric (15) (idic(15)) syndrome Patient 1. suffered from bigeminic extrasystoles and had postnatal growth retardation, which had been published only in a few articles.

Conclusions: Dosage effect of some genes in the concerned genomic region is known, but several genes have no evidence to have dosage dependence. Our results expanded the previous literature data. We assume dosage dependence in the case of CHRNA7 and OTUDTA, which might be involved in growth regulation. On the other hand increased dosage of the KLF13 gene seems to have no direct causal relationship with heart morphology. The genomic environment of the affected genes may be responsible for the observed phenotype.
\end{abstract}

Keywords: Array CGH, Epilepsy, Dysmorphism, 15q duplication syndrome, Supernumerary chromosome

\section{Background}

Karyotyping and FISH are essential parts of the clinical evaluation of patients with epilepsy and dysmorphic features. FISH investigation is necessary in cases where (bi)satellited supernumerary chromosome is present in order to establish the chromosomal origin and the involvement of Prader-Willi/Angelman region (PWACR) in those with proven chromosome 15 (chr15) material. Increasing usage of array comparative genomic hybridization (array CGH) in the examination of patients with epilepsy and dysmorphic features allows the determination of the correlation between phenotype and genotype. Clinical studies investigated the function of chromosomal

\footnotetext{
* Correspondence: melegh.bela@pte.hu

${ }^{1}$ Department of Medical Genetics, University of Pecs, Szigeti 12, H-7624 Pecs, Hungary

${ }^{2}$ Szentagothai Research Centre, Ifjusag 20, H-7624 Pecs, Hungary
}

microarray analysis in the diagnosis of patients with epilepsy, and described an association between chromosomal copy number variations, intrachromosomal rearrangements and epileptic features [1]. Nevertheless, the genetic background of dysmorphic features remains unidentified despite the extensive investigation. This complex disease is associated with several previously described chromosomal alterations.

Small supernumerary marker chromosomes derived from the chr15 (sSMC(15)s) has been more frequently reported in connection with dysmorphic features and cause several phenotypes including intellectual disability, growth deficiency, triangular facies, and brachydactyly $[2,3]$. During the formation of this $\operatorname{sSMC}(15)$ a translocation occurs between the homolog chr15s, typically in the course of maternal meiosis, mediated by the low copy repeats being present within 15q11-q14. The following 
step is a non-disjunction and usually inactivation of one of the centromeres. Due to postzygotic correction a mosaic state is not uncommon. Within the $15 \mathrm{q} 11 \mathrm{q} 14$ region five common breakpoints were identified (BP1 to BP5). The classification of $\mathrm{sSMC}(15) \mathrm{s}$ is based on the euchromatin content (namely on the site of recombination). In contrast with the small sSMC(15)s containing the chromosomal material proximal to $15 \mathrm{q} 12$ and being clinically neutral, the larger $\mathrm{sSMC}(15) \mathrm{s}$ resulting in partial trisomy or tetrasomy of Prader-Willi/Angelman region cause abnormal phenotype, in particular when of maternal origin [4]. Symptoms can vary depending on location of the breakpoints, copy numbers of the PWACR region and on the ratio of mosaicism. Clinical phenotype mostly includes early-onset central hypotonia, seizures, poor motor coordination, speech delay, moderate to severe learning disability, mild dysmorphic features, autism and schizophrenia [5-18]. Cytogenetically visible duplications (OMIM \#608636) of this region are also reported, and lead to a disorder called 15q duplication syndrome, mostly manifested by neurobehavioral phenotypes [19]. These duplications occur mostly in two forms, including an extra isodicentric 15 (idic (15)) chromosome or an interstitial duplication 15. Based on previous literature data we can assume that patients with idic (15) of paternal origin seem to have normal development however, maternal aberrations can lead to developmental problems $[4,20,21]$. In most of the cases the $15 q$ duplication syndrome is not inherited, but occurs randomly during the formation of reproductive cells. Wide range of developmental disabilities was experienced in the case of the individuals with $15 \mathrm{q}$ duplication syndrome. Examinations of the syndrome could not show an obvious correlation between the severity of the symptoms and the size of the duplicated region. Copy number changes of this chromosomal region from three to six have been reported in the literature $[4,22,21]$.

In order to establish the chromosomal content more precisely, we applied array CGH investigation of two Hungarian patients.

\section{Case Presentation}

\section{Patients}

We investigated 2 unrelated Hungarian patients with epilepsy and dysmorphic features.

Patient 1. is a 27 month old boy, first child of a nonconsanguineous healthy young couple (father is 32 and mother is 31 years old), the mother has a boy from her first marriage. The family history and the pregnancy were unremarkable. He was delivered at the 40th week of gestation with a birth weight of $3200 \mathrm{~g}(25-50 \mathrm{pc})$ and an Apgar score 9/1 and 10/5, respectively. In the perinatal period cardiological examination was performed because of extrasystole. The Holter monitoring revealed bigeminic extrasystoles, but it regressed spontaneous shortly. His first epileptic seizure developed at 5.5 months of age, and he was never seizure free in spite of numerous different antiepileptic drug combinations. His seizure pattern is very variable, and at four years of age hyperactivity developed. His developmental milestones were delayed, he crept and stood at 18 months, but he could not walk. Speech development was delayed as well, only bubbling was present at 28 months.

At 28 months of age as he was first examined in our institution, his weight was $10 \mathrm{~kg}(<5 \mathrm{pc})$, height was $90 \mathrm{~cm}(50-75 \mathrm{pc})$ and OFC was $46 \mathrm{~cm}(<-2 \mathrm{SD})$. Flat occipital region, epicanthal folds, hyperteloristic eyes, crease of earlobes, broad nasal bridge, micrognathia and severe generalized hypotonia were present.

Patient 2. is a 17 months old girl from the second pregnancy (G2P1) of a non-consanguineous healthy young Caucasian couple (both parents are 32 years old), the family history is unremarkable. The girl was delivered at 41st weeks of gestation with a birth weight of $3520 \mathrm{~g}(75-90 \mathrm{pc})$ and Apgar score $1 / 10$ and 5/10. The perinatal period was uneventful. Because of developmental delay she received neurohabilitation from the fourth month of age and West syndrome developed at the sixth month. Therefore vigabatrin treatment was administered, which caused significant seizure frequency reduction. Congenital brain malformation was supposed in the background but the performed brain MRI out of dilated frontal and temporal liquor spaces gave negative results. Her developmental milestones were delayed. At 12 months she sat alone and crawled, at 13 months she stood up, but at 17 months her walking capability was yet very unstable. Her speech development was severely delayed too.

She was referred to our institution because of epilepsy, dysmorphic features and developmental delay at the age of 17 months. At the examination her weight was $13 \mathrm{~kg}$ (90 pc), height $85 \mathrm{~cm}(75-90 \mathrm{pc})$, OFC $46 \mathrm{~cm}(-1 \mathrm{SD})$, and only mild craniofacial dysmorphic signs (prominent forehead, flat occiput, broad face, turned-up nose), broad thorax and small feet could be observed. In her neurological status severe generalized hypotonia, tiptoe walking and stereotype hand movements (clapping and wringing of the hands) were seen.

At her second examination at 29 month of age she could not walk alone and her walk was yet broad-base. Babbling started, but she had no clear words. Her stereotype movements were constant, but her seizure pattern and the frequency were changed. Therefore valproic acid was administered instead of vigabatrin.

\section{Results}

GTG banding and FISH

GTG-banded chromosomes at the (550)-band level showed E-group sized supernumerary acrocentric marker 
chromosome in Patient 1. and an additional bisatellited chromosome in Patient 2. Because of the clinical symptoms/clinical indication metaphase FISH analyses of the UBE3A locus (Prader-Willi/Angelman Critical Region) was performed in both cases which showed the presence of both, the D15Z1 and UBE3A regions (each in two copies) on the supernumerary marker chromosomes in addition to the normal chromosomes 15 (four copies in all in each cells) (Figure 1). Thus, the karyotype of Patient 1. can be described as 47,XY,+psu idic (15) (pter $\rightarrow$ q14::q14 $\rightarrow$ pter) and that of Patient 2. is $47, \mathrm{XX},+$ idic (15)(pter $\rightarrow$ q14::q14 $\rightarrow$ pter). Both abnormalities resulted in tetrasomy of the 15q11q13 region.

Parental cytogenetic studies were normal.

\section{UPD study}

Uniparental disomy of normal chromosomes 15 has been excluded using polymorphic STR markers. None of the two patients has uniparental disomy.

\section{Array-based copy number analysis}

Array CGH of Patient 1. showed an abnormal male array profile with copy number gain in the region 15q11.2q13.3 $(22,765,628-32,445,252)$, while in Patient 2. an abnormal female profile with additional dosage of the regions 15q11.2q13.2 (22,765,628-31,183,907) and 15q13.3 $(31,261,835-32,861,626)$, respectively (Figure 2$)$.
Both two investigated patients had gain in copy number of the 15q11.2q13.3 chromosomal region. Patient 1 . had 4 copies of 15q11.2q13.3 (9.68 Mb, chr15:22,765,628$32,445,252)$, Patient 2 . had 4 copies of $15 \mathrm{q} 11.2 \mathrm{q} 13.2$ $(8.42 \mathrm{Mb}$, chr15:22,765,628-31,183,907) and of $15 \mathrm{q} 13.3$ (1.6 Mb, chr15:31,261,835-32,861,626) chromosomal regions, demonstrating that the psu idic(15) contained two 9.68 Mb 15q11.2q13.3 segments (chr15:22,765,628$32,445,252)$ in Patient 1. and the + idic(15) contained two 15q11.2q13.2 segments with 8.42 Mb (chr15:22,765,628$31,183,907)$ and 1.6 $\mathrm{Mb}$ of 15q13.3 (chr15:31,261,83532,861,626) regions in Patient 2.

\section{Discussion}

Alterations of the 15q11.2q13.3 chromosomal region lead to a complex phenotypic variability, which greatly complicates the setting of a specific clinical diagnose. Here we present the results of the first study of array $\mathrm{CGH}$ analysis in Hungarian patients with epileptic seizures, delayed development, hyperactivity and craniofacial dysmorphic signs where the copy number gain of the region 15q11.2q13.3 (22,765,628-32,445,252) (Patient 1.), and that of $15 \mathrm{q} 11.2 \mathrm{q} 13.2(22,765,628-31,183,907)$ and 15q13.3 (31,261,835-32,861,626) (Patient 2.) have been identified in the background of the abnormal phenotype.

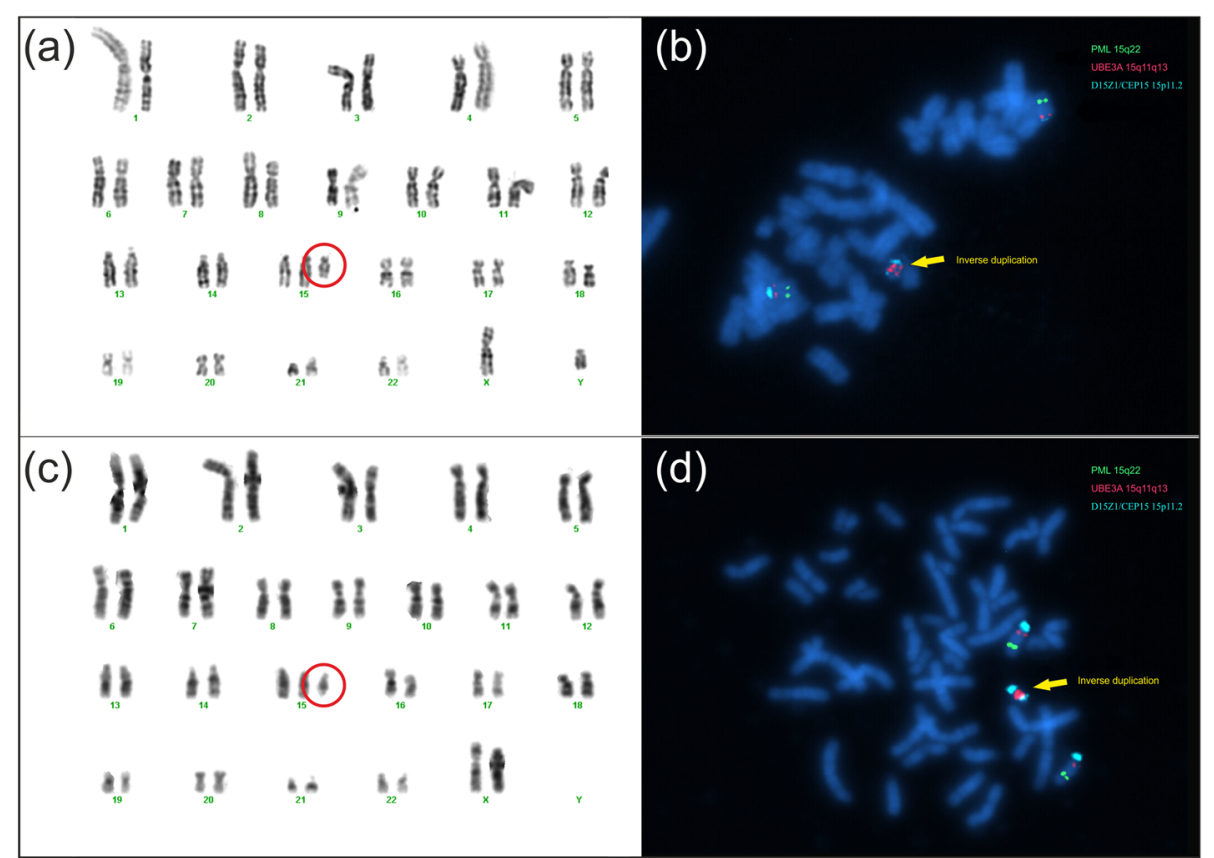

Figure 1 Karyotype and FISH analysis. (a) Karyotype of Patient 1. illustrates the supernumerary chromosome 15. (b) FISH analysis of Patient 1. by using probes for UBE3A locus (red) at 15q11q13, D15Z1/CEP15 locus (cyan) at 15p11.2 and PML locus (green) at 15q22 illustrates the tetrasomy of chromosome 15q11q13. (c) Karyotype of Patient 2. illustrates the supernumerary chromosome 15. (d) FISH analysis of Patient 2. by using probes for UBE3A locus (red) at 15q11q13, D15Z1/CEP15 locus (cyan) at 15p11.2 and PML locus (green) at 15q22 illustrates the tetrasomy of chromosome 15q11q13 


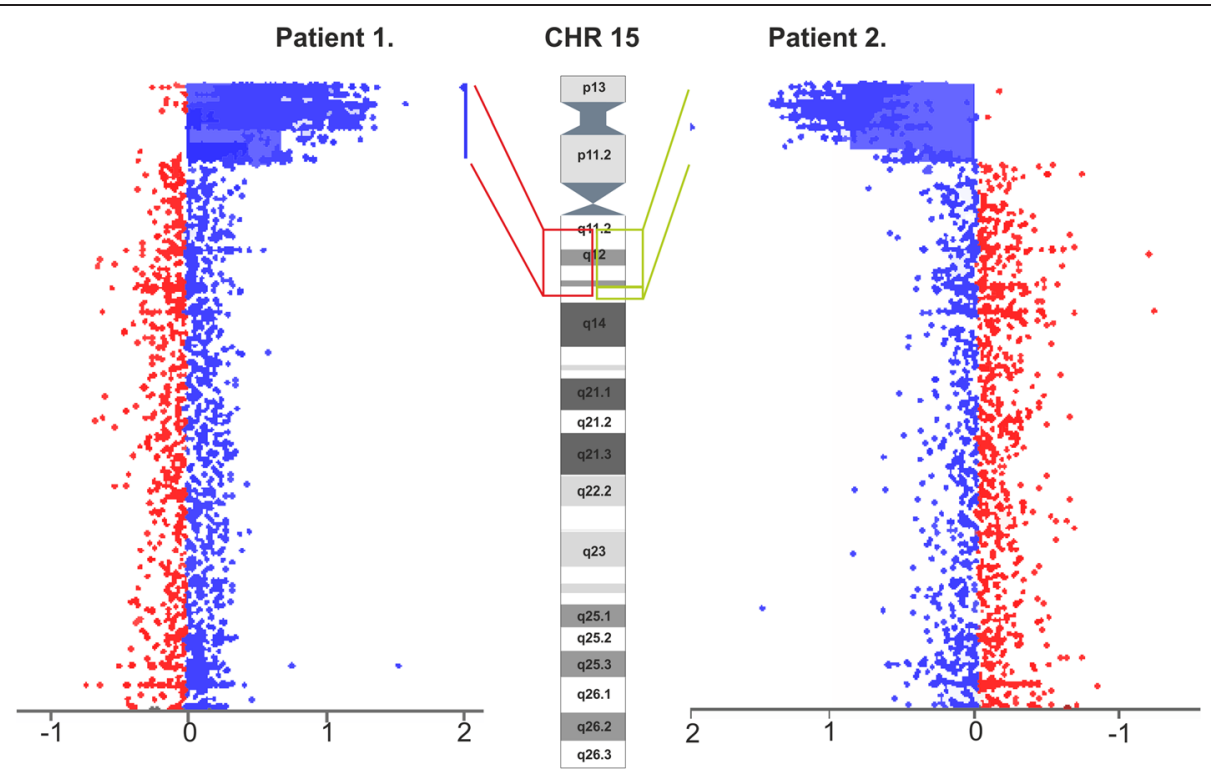

Figure 2 Array-CGH results of the two Hungarian cases. Figure shows the copy number gain of 15q11q13 region in Patient 1 (left) and in Patient 2 (right). Red box illustrates the localization of the copy number gain in Patient1 on chromosome 15. Green box illustrates the positions of the copy number gains in Patient 2. on chromosome 15

All of the protein coding genes, occurring in the 15q11.2q13.3 (22,765,628-32,861,626) duplicated region are shown in the Additional file 1: Table 1 and Figure 3. Genes within the affected regions are significantly linked to identified clinical disorders, mainly developmental, hereditary and neurological disorders. (Additional file 2: Table 2).

Based on our findings and previous literature data, we concluded, that most of the genes within the affected regions are significantly associated with the phenotypic features of the two analyzed patients. Hypotonia, delayed motor milestones (sitting up, walking), delayed language development, progressed hypertonia, and similar facial characteristics, including flat nasal bridge, epicanthic and hyperteloristic eyes in Patient 1. can assume a 15q duplication syndrome that affected the 15q11.2q13.3 $(22,765,628-32,445,252)$ chromosomal region [21]. In addition to the symptoms were seen in Patient 1., Patient 2. represented typical Angelman like features including

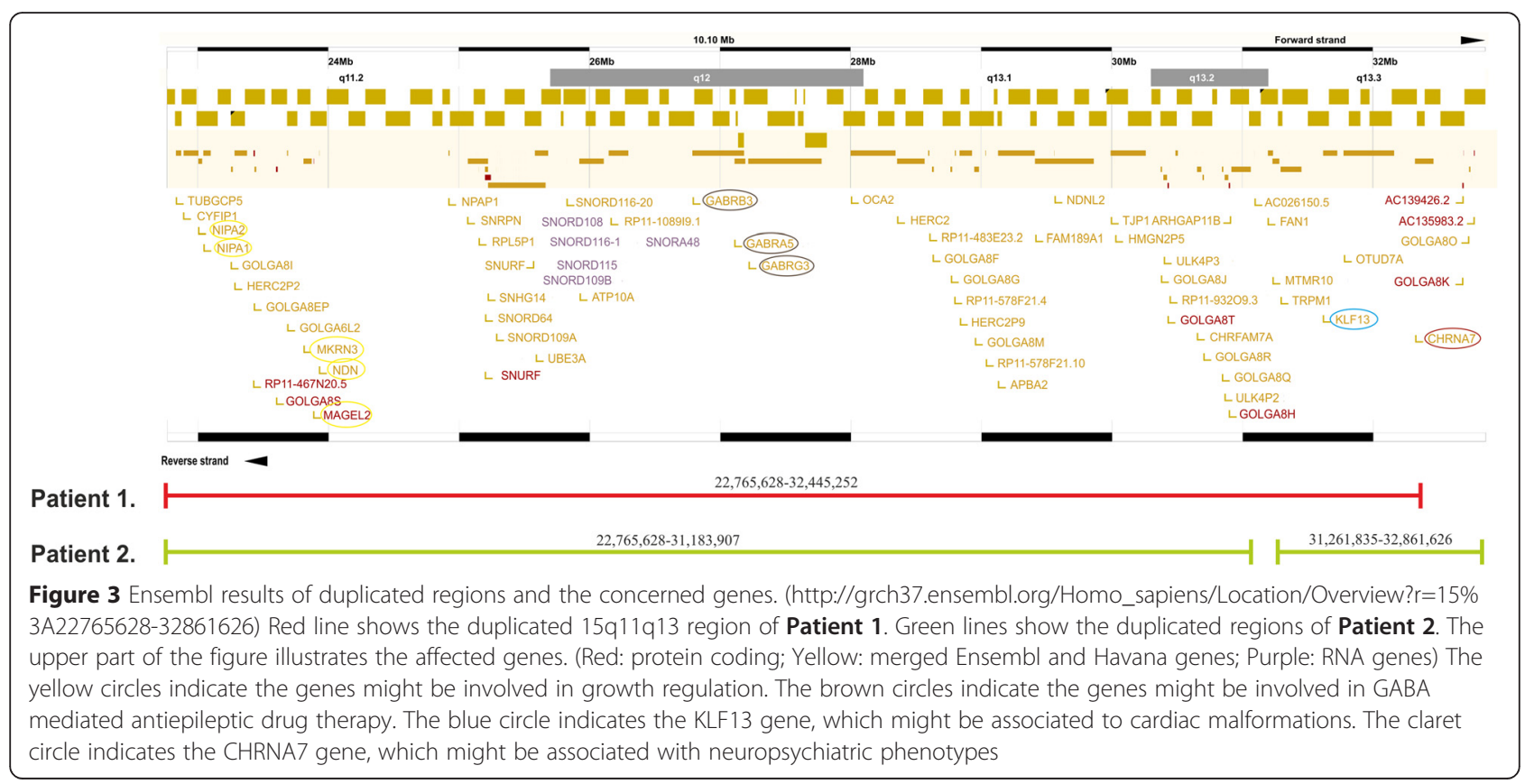


small feet, turned-up nose, tiptoe walking and stereotype hand movements (clapping and wringing of the hands).

After uneventful prenatal period, both of our patients had normal birth weight. By comparing our cases with the recently published patients investigated by array $\mathrm{CGH}$ and affected by $15 \mathrm{q}$ duplication syndrome we could identify more defined postnatal growth retardation in the case of Patient 1. (Additional file 3: Table 3). At 28 months of age his weight was only $10 \mathrm{~kg}(<5 \mathrm{pc})$, height was $90 \mathrm{~cm}(50-75 \mathrm{pc})$ and OFC was $46 \mathrm{~cm}(<-2$ SD) comparing to Patient 2. with a $13 \mathrm{~kg}(90 \mathrm{pc}$ ) weight at age 17 months. On the contrary of the previous reported cases our Patient 1 . had normal birth weight and the growth delay occurred subsequently. Proportional short stature was mentioned previously in many cases, but postnatal growth delay associated with low weight was observed to the best of our knowledge only in one 15q13.3 duplicated patient (DECIPHER), in which CHRNA7 and OTUD7A genes have found within the duplicated chromosomal region. The role of the cholinergic nicotinic receptor CHRNA7 gene has been attributed in neuropsychiatric disorders, epilepsy, cognitive impairment, furthermore, it is essential for inhibiting cytokine synthesis by the cholinergic anti-inflammatory pathway [23]. Dosage sensitivity of the gene has been reported in patients with 15q13.3 deletion in several cases, among them in a West-syndrome patient recently [24], and proved by Valbonesi et al. [25] in a cohort of ADHD patients where deletion and the resulting lower gene expression level was investigated. In a three-generation family with various neuropsychiatric phenotypes, copy number gain of CHRNA7 showed co-segregation with the symptoms [26]. Our data/cases provide further evidence for the pathogenicity of copy number gain. Literature data of the intronless NDN, MAGEL2, MKRN3 and the NIPA1, NIPA2 genes confirm that these genes are involved in growth regulation, nervous system development or transcription. Deletion of the genes in mice and humans presents failure in nervous system development and growth regulation [27-29]. Increased dosage of the mentioned genes could play a role in the development of postnatal growth retardation.

The group of congenital heart defects is one of the most common causes of infant morbidity and mortality with an estimated prevalence of $1-5 \%$ of life births. Congenital heart defects caused by idic (15) duplication syndrome occur in about $25 \%$ of the cases [4] and 7-18\% of patients with the 15q13.3 deletion syndrome (OMIM 612001) had heart defects [30,17,31,32]. Clinical findings from $15 \mathrm{q}$ microdeletion cases pointed that mitral valve prolapse, slightly enlarged left ventricle, tetralogy of Fallot and right cardiac hypoplasia with severe tricuspid stenosis could develop by the deletion of the KLF13 gene of the BP4BP5 chromosomal region. Kruppel-like transcription
Factor 13 is a well conserved gene, which encodes a member of the Kruppel-like family of zinc-finger proteins. The protein is identified as a regulator of cardiac gene expression and heart morphogenesis [33,17]. Genetic studies in the Xenopus embryos also demonstrated a requirement for KLF13 in cardiac progenitor cell proliferation and heart morphogenesis [34]. In KLF13 functional knockout Xenopus embryos normal initial heart development was observed but, subsequently, the heart was visibly smaller and showed several defects including a lack of ventricular trabeculation, atrial septal defects, delayed atrioventricular cushion formation and maturation of valves [34]. Derwińska et al. presented a $1.6 \mathrm{Mb} 15 \mathrm{q} 13.3$ duplication in a patient having cardiac phenotype and suggested that increased dosage of KLF13 could be the causative of cardiac anomalies [35]. In our case neither patient showed cardiac anomalies, although Patient 1. did present bigeminic extrasystole. Based on the limited data available and on our results, we cannot support Derwińska's findings about the association between the increased KLF13 dosage and cardiac malformations.

Concerning the dosage sensitivity Hamid et. al. reported in the context of pericentric human chromosomal regions, that dosage dependent and dosage independent genes could stand in the background of the clinical effects of the sSMCs. He stated, that sSMCs containing only dosage independent genes could be harmless, while dosage dependent genes in the marker chromosomes could lead to clinical problems [36].

Regarding to the epilepsy specific treatment of the patients, antiepileptic drug therapy, using gamma aminobutyric acid transaminase inhibitor vigabatrin and valproic acid was effective. GABA acts at inhibitory synapses in the brain by binding to specific transmembrane receptors. Both of our patients have a gain in the GABA receptor subunit coding GABRB3, GABRA5 and GABRG3 genes, which could lead to an increased GABA receptor level. The used antiepileptic drugs increase the level of the GABA protein, by inhibiting the GABA metabolism of GABA transaminases. The higher receptor number associated with the increased GABA level could be a possible explanation for the reduced seizure frequency due to the successful treatment [37-39].

An other database was available [40] containing data of 43 cases with inv dup (15) and seizures. However in this database 42 cases were investigated only with simple karyotyping and only one with array CGH. Additional file 3: Table 3. contains this case. The other 42 patients, thus could be compared to our cases only based on the phenotype. Phenotypic manifestation was mostly the same in our cases and the examined patients, except the presence of defined postnatal growth retardation in the case of Patient 1. The lack of array CGH results could not allow the clarification of the gene-phenotype relationship. 


\section{Conclusions}

We identified the first two array CGH examined Hungarian patients with tetrasomy of the proximal region of chromosome 15. Alterations of the 15q11.2q13.3 chromosomal region cause complex phenotypic variability, which greatly complicates the setting of a specific clinical diagnose. FISH analysis followed by array CGH provided clinically relevant information of the investigated patients. The copy number gain of the 15q11.2q13.3 chromosomal region could explain the phenotypic presentations characteristic for idic (15) syndrome observed in the patients, including epileptic seizures, delayed development, hyperactivity and craniofacial dysmorphic signs.

In case of a number of genes in the affected chromosomal regions dosage effect evidence was reported, however for certain genes, dosage dependence is not proven. Based on our findings, we could provide additional information for previous literature data in case, that increased dosage of CHRNA7 and OTUD7A genes could lead to postnatal growth delay, so dose dependence of these genes could be assumed. In contrast, dosage dependence of the KLF13 gene in a patient with an $1.6 \mathrm{Mb}$ duplication involving the KLF13 gene and in KLF13 knockout Xenopus embryos was presumable, while none of our patients with higher copy number of KLF13 showed cardiac anomalies. Thus, our results could not verify the dosage dependence of the KLF13 gene. However it could be concluded, that not only the size of the duplicated region, but the gene content could be responsible for the whole clinical manifestation. Based on our results we can assume, that in case of these genes the development of the expected clinical features could be much better influenced by the copy number of the genes and their genomic environment, than only the size of the duplicated genetic material itself. Nevertheless, in the case of NDN, MAGEL2, MKRN3 and the NIPA1, NIPA2 genes confirmation is needed for the causal relationship between copy number gain and postnatal growth delay.

Further investigations are necessary to get better knowledge regarding to the association between the detailed genes and the phenotypes they might cause and to the dosage sensitivity of individual genes affected by the aberrations.

\section{Materials And Methods GTG banding}

Karyotyping of the patient was performed by GiemsaTrypsin (GTG) banding from peripheral blood lymphocytes using standard procedures [41].

\section{Fluorescent in situ hybridization (FISH)}

We performed fluorescence in situ hybridization for the investigation of the supernumerary marker chromosome, using the 15q11-q13 (D15S10/UBE3A) Prader-Willi/
Angelman probe with 15p11.2 (D15Z1/CEP15) and 15q22 (PML) as control probes (Vysis, Abbott Laboratories, Abbott Park, Illinois, U.S.A.) [42].

\section{Uniparental disomy study}

Uniparental disomy of chromosomes 15 was examined using previously reported D15S11, D15S97, D15S122, D15S113, D15S659, D15S128, D15S210, D15S165, D15S10 and GABRB3 polymorphic STR markers [43,44].

\section{Array CGH}

Agilent Human Genome Unrestricted G3 ISCA v2 Sureprint 8x60K oligo-array (Amadid 031746) (Agilent, Santa Clara, CA) was used for array CGH [45]. This high resolution microarray contains 18,851 60-mer oligo probes in ISCA regions $+40,208$ backbone probes including coding and non-coding genomic sequences with an average $60 \mathrm{~KB}$ overall median probe spacing, respectively (higher in ISCA regions).

DNA purification from blood was performed using the NucleoSpin Dx Blood DNA Purification Kit (ThermoFisher Scientific, Waltham, MA) applying the protocol of the producer. We measured the concentration and purity of the isolated DNA with the NanoDrop spectrophotometer. For labelling and for hybridization we used the Agilent Oligonucleotide Array-Based CGH for Genomic DNA Analysis - Enzymatic Labelling Protocol. $1 \mu \mathrm{g}$ from the patient DNA and from a sex-matched reference DNA were digested for $2.5 \mathrm{hrs}$ at $37^{\circ} \mathrm{C}$ with AluI and RsaI enzymes. For the labelling of the digested DNA we applied random priming using the Agilent Genomic DNA Labelling Kit (Agilent, Santa Clara, CA). Patient and control DNA were labelled differently. Cy5-dUTP was used for labelling the patient samples and Cy3dUTP for the control samples. Labelled DNA samples were purified by Amicon Ultra AU-30 filters. The patient and sex-matched reference samples were combined and cohybribized at $65^{\circ} \mathrm{C}$ for $24 \mathrm{hrs}$ rotation with $50 \mu \mathrm{g} \mathrm{Hu}$ man Cot-1 DNA. Washing step was performed using the Agilent Protocol v7.2. Array image was obtained using an Agilent laser scanner G2565CA and analysed with the Agilent FeatureExtraction software (v10.10.1.1.).

The results were presented by Agilent Cytogenomics software (v2.5.8.11). DNA sequence information refers to the public UCSC database. The detected chromosomal changes were aligned to known aberrations listed in publicly available databases. We used the DECIPHER (Database of Chromosomal Imbalance and Phenotype in Humans using Ensembl Resources), the Database of Genomic Variants, Ensembl and ECARUCA.

\section{Consent}

Written informed consent was obtained from the patient for publication of this Case report and any accompanying 
images. A copy of the written consent is available for review by the Editor-in-Chief of this journal.

\section{Additional files}

Additional file 1: Table 1. Function of protein coding genes of the $15 q 11.2 q 13.3(22,765,628-32,861,626)$ chromosomal region according to Decipher. (https://decipher.sanger.ac.uk/) Notes: Bold: OMIM genes; Italic: Morbid genes; HI(D): Haploinsufficiency scores from Decipher: values from 0-100\%. Low values (0-10\%) indicate more likely to exhibit Haploinsufficiency. The $\mathbf{a}$ labeling indicates the genes might be involved in growth regulation. The $\boldsymbol{\beta}$ labeling indicates the genes might be involved in GABA mediated antiepileptic drug therapy. The $\boldsymbol{\gamma}$ labeling indicates the KLF13 gene, which might be associated to cardiac malformations. The $\boldsymbol{\delta}$ labeling indicates the CHRNA7 gene, which might be associated with neuropsychiatric phenotypes.

Additional file 2: Table 2. The list of the genes located in the duplicated regions and the associated diseases.

Additional file 3: Table 3. Comparing clinical features of array CGH investigated 15q11q13 duplication patients and our cases. a labeling indicates the postnatal growth retardation phenotype, while $\boldsymbol{\gamma}$ labeling indicates the cardiac symptom of Patient 1.

\section{Abbreviations}

Array CGH: Array comparative genomic hybridization; idic(15): Isodicentric chromosome 15; PWACR: Prader-Willi/Angelman critical region; Chr15: Chromosome 15; sSMC(15): Small supernumerary marker chromosome derived from chromosome 15; FISH: Fluorescent in situ hybridization; ASD: Atrial septum defect; VSD: Ventral septum disease; MRI: Magnetic Resonance Image; EEG: Electroencephalography; GTG banding: Giemsa Banding; GRCh37:hg 19: Genome Reference Consortium human 37/human genome 19; UCSC database: University of California, Santa Cruz Genome Browser database; DECIPHER: Database of Chromosomal Imbalance and Phenotype in Humans using Ensembl Resources; DGV: Database of Genomic Variants; ECARUCA: European Cytogeneticists Association Register of Unbalanced Chromosome Aberrations.

\section{Competing Interests}

The author(s) declare that they have no competing interests.

\section{Authors' Contributions}

$\mathrm{KH}$ and $\mathrm{KK}$ were responsible for the patient's clinical genetic examination. $\mathrm{KH}$ and KK contributed to the clinical description. BM, MCZ, BD and ASz conceived and designed the molecular experiments. MCz, BD and ASz performed the array $\mathrm{CGH}$ and analyzed the data. $\mathrm{ASz}, \mathrm{MCz}, \mathrm{KH}, \mathrm{BD}, \mathrm{KK}$, and $\mathrm{BM}$ co-wrote the manuscript and revised critically for important intellectual content. All authors read and approved the final manuscript.

\section{Acknowledgements}

This research was supported by the European Union and the State of Hungary, co-financed by the European Social Fund in the framework of TÁMOP-4.2.4.A/ 2-11/1-2012-0001 'National Excellence Program' and by the János Bolyai Research Scholarship of the Hungarian Academy of Sciences to KK. The acquisition of equipment was supported by the OTKA 103983.

\section{Received: 27 February 2015 Accepted: 21 April 2015}

\section{Published online: 25 June 2015}

\section{References}

1. Moon HJ, Yim SV, Lee WK, Jeon YW, Kim YH, Ko YJ, et al. Identification of DNA copy-number aberrations by array-comparative genomic hybridization in patients with schizophrenia. Biochem Biophys Res Commun. 2006;344(2):531-9. doi:10.1016/j.bbrc.2006.03.156.

2. Nicholls RD, Knoll JH, Butler MG, Karam S, Lalande M. Genetic imprinting suggested by maternal heterodisomy in nondeletion Prader-Willi syndrome. Nature. 1989;342(6247):281-5. doi:10.1038/342281a0.

3. Roback EW, Barakat AJ, Dev VG, Mbikay M, Chretien M, Butler MG. An infant with deletion of the distal long arm of chromosome 15 (q26.1--qter) and loss of insulin-like growth factor 1 receptor gene. Am J Med Genet. 1991;38(1):74-9. doi:10.1002/ajmg.1320380117.

4. Battaglia A. The inv dup (15) or idic (15) syndrome (Tetrasomy 15q). Orphanet J Rare Dis. 2008:3:30. doi:10.1186/1750-1172-3-30.

5. Roberts SE, Maggouta F, Thomas NS, Jacobs PA, Crolla JA. Molecular and fluorescence in situ hybridization characterization of the breakpoints in 46 large supernumerary marker 15 chromosomes reveals an unexpected level of complexity. Am J Med Genet. 2003;73(5):1061-72. doi:10.1086/379155.

6. Liehr T, Brude E, Gillessen-Kaesbach G, Konig R, Mrasek K, von Eggeling F, et al. Prader-Willi syndrome with a karyotype 47, XY,+min(15)(pter-> q11.1:) and maternal UPD 15-case report plus review of similar cases. Eur J Med Genet. 2005;48(2):175-81. doi:10.1016/j.ejmg.2005.01.004.

7. Cotter PD, Ledesma CT, Dietz LG, Pusso S, Wohlferd MM, Goldberg JD. Prenatal diagnosis of supernumerary marker 15 chromosomes and exclusion of uniparental disomy for chromosome 15. Prenat Diagn. 1999;19(8):721-6.

8. Dennis NR, Veltman MW, Thompson R, Craig E, Bolton PF, Thomas NS. Clinical findings in 33 subjects with large supernumerary marker(15) chromosomes and 3 subjects with triplication of 15q11-q13. Am J Med Genet A. 2006;140(5):434-41. doi:10.1002/ajmg.a.31091.

9. Borelina D, Esperante S, Gutnisky V, Ferreiro V, Ferrer M, Giliberto F, et al Supernumerary marker 15 chromosome in a patient with Prader-Willi syndrome. Clin Genet. 2004;65(3):242-3.

10. Mann SM, Wang NJ, Liu DH, Wang L, Schultz RA, Dorrani N, et al. Supernumerary tricentric derivative chromosome 15 in two boys with intractable epilepsy: another mechanism for partial hexasomy. Hum Genet. 2004;115(2):104-11. 10.1007/s00439-004-1127-5.

11. Huang XL, de Michelena MI, Mark H, Harston R, Benke PJ, Price SJ, et al. Characterization of an analphoid supernumerary marker chromosome derived from 15q25-qter using high-resolution CGH and multiplex FISH analyses. Clin Genet. 2005;68(6):513-9. doi:10.1111/j.1399-0004.2005.00523.x.

12. Cheng SD, Spinner NB, Zackai EH, Knoll JH. Cytogenetic and molecular characterization of inverted duplicated chromosomes 15 from 11 patients. Am J Med Genet. 1994;55(4):753-9.

13. Rineer S, Finucane B, Simon EW. Autistic symptoms among children and young adults with isodicentric chromosome 15. Am J Med Genet. 1998;81(5):428-33.

14. McGinniss MJ, Brown DH, Burke LW, Mascarello JT, Jones MC. Ring chromosome $\mathrm{X}$ in a child with manifestations of Kabuki syndrome. Am J Med Genet. 1997;70(1):37-42.

15. Cockwell AE, Davalos IP, Rivera HR, Crolla JA. FISH characterisation of dynamic mosaicism involving an inv dup(15) in a patient with mental retardation. Am J Med Genet. 2001;103(4):289-94.

16. Shibuya $Y$, Tonoki H, Kajii N, Niikawa N. Identification of a marker chromosome as inv dup(15) by molecular analysis. Clin Genet. 1991;40(3):233-6.

17. van Bon BW, Mefford HC, Menten B, Koolen DA, Sharp AJ, Nillesen WM, et al. Further delineation of the $15 q 13$ microdeletion and duplication syndromes: a clinical spectrum varying from non-pathogenic to a severe outcome. J Med Genet. 2009;46(8):511-23. doi:10.1136/jmg.2008.063412.

18. Hogart A, Leung KN, Wang NJ, Wu DJ, Driscoll J, Vallero RO, et al. Chromosome 15q11-13 duplication syndrome brain reveals epigenetic alterations in gene expression not predicted from copy number. J Med Genet. 2009;46(2):86-93. doi:10.1136/jmg.2008.061580.

19. Battaglia A, Parrini B, Tancredi R. The behavioral phenotype of the idic(15) syndrome. Am J Med Genet C: Semin Med Genet. 2010;154C(4):448-55. doi:10.1002/ajmg.c.30281.

20. Moeschler JB, Mohandas TK, Hawk AB, Noll WW. Estimate of prevalence of proximal 15q duplication syndrome. Am J Med Genet. 2002;111(4):440-2. doi:10.1002/ajmg.10419.

21. Yang J, Yang $Y$, Huang $Y$, Hu Y, Chen $X$, Sun $H$, et al. A study of two Chinese patients with tetrasomy and pentasomy $15 q 11$ q13 including Prader-Willi/Angelman syndrome critical region present with developmental delays and mental impairment. BMC Med Genet. 2013;14:9. doi:10.1186/ 1471-2350-14-9.

22. Wang NJ, Liu D, Parokonny AS, Schanen NC. High-resolution molecular characterization of 15q11-q13 rearrangements by array comparative genomic hybridization (array $\mathrm{CGH}$ ) with detection of gene dosage. Am J Med Genet. 2004;75(2):267-81. doi:10.1086/422854.

23. Wang H, Yu M, Ochani M, Amella CA, Tanovic M, Susarla S, et al. Nicotinic acetylcholine receptor alpha7 subunit is an essential regulator of inflammation. Nature. 2003;421(6921):384-8. doi:10.1038/nature01339. 
24. Lacaze E, Gruchy N, Penniello-Valette MJ, Plessis G, Richard N, Decamp M, et al. De novo 15q13.3 microdeletion with cryptogenic West syndrome. Am J Med Genet A. 2013;161A(10):2582-7. doi:10.1002/ajmg.a.36085.

25. Valbonesi S, Magri C, Traversa M, Faraone SV, Cattaneo A, Milanesi E, et al. Copy number variants in attention-deficit hyperactive disorder: identification of the 15q13 deletion and its functional role. Psychiatr Genet. 2014. doi:10.1097/YPG.0000000000000056.

26. Soler-Alfonso C, Carvalho CM, Ge J, Roney EK, Bader PI, Kolodziejska KE, et al. CHRNA7 triplication associated with cognitive impairment and neuropsychiatric phenotypes in a three-generation pedigree. Eur J Med Genet: EJHG. 2014;22(9):1071-6. doi:10.1038/ejhg.2013.302.

27. Lui JC, Finkielstain GP, Barnes KM, Baron J. An imprinted gene network that controls mammalian somatic growth is down-regulated during postnatal growth deceleration in multiple organs. Am J Physiol Regul Integr Comp Physiol. 2008;295(1):R189-96. doi:10.1152/ajpregu.00182.2008.

28. Tsang HT, Edwards TL, Wang X, Connell JW, Davies RJ, Durrington HJ, et al. The hereditary spastic paraplegia proteins NIPA1, spastin and spartin are inhibitors of mammalian BMP signalling. Hum Mol Genet. 2009;18(20):3805-21. doi:10.1093/hmg/ddp324.

29. Skryabin BV, Gubar LV, Seeger B, Pfeiffer J, Handel S, Robeck T, et al. Deletion of the MBII-85 snoRNA gene cluster in mice results in postnatal growth retardation. PLoS Genet. 2007;3(12), e235. doi:10.1371/journal. pgen.0030235.

30. Sharp AJ, Mefford HC, Li K, Baker C, Skinner C, Stevenson RE, et al. A recurrent 15q13.3 microdeletion syndrome associated with mental retardation and seizures. Nat Genet. 2008;40(3):322-8. doi:10.1038/ng.93.

31. Masurel-Paulet A, Andrieux J, Callier P, Cuisset JM, Le Caignec C, Holder M, et al. Delineation of 15q13.3 microdeletions. Clin Genet. 2010;78(2):149-61. doi:10.1111/j.1399-0004.2010.01374.x.

32. Campos CM, Zanardo EA, Dutra RL, Kulikowski LD, Kim CA. Investigation of Copy Number Variation in Children with Conotruncal Heart Defects. Arquivos brasileiros de cardiologia. 2014;104(1):24-31.

33. Lavallee G, Andelfinger G, Nadeau M, Lefebvre C, Nemer G, Horb ME, et al. The Kruppel-like transcription factor KLF13 is a novel regulator of heart development. EMBO J. 2006;25(21):5201-13. doi:10.1038/sj.emboj.7601379.

34. Nemer M, Horb ME. The KLF family of transcriptional regulators in cardiomyocyte proliferation and differentiation. Cell Cycle. 2007;6(2):117-21.

35. Derwinska K, Bartnik M, Wisniowiecka-Kowalnik B, Jagla M, Rudzinski A, Pietrzyk JJ, et al. Assessment of the role of copy-number variants in 150 patients with congenital heart defects. Med Wieku Rozwoj. 2012;16(3):175-82.

36. Hamid A, Weise A, Voigt M, Bucksch M, Kosyakova N, Liehr T, et al. Clinical impact of proximal autosomal imbalances. Balkan j med gen : BJMG. 2012;15(2):15-22. doi:10.2478/bjmg-2013-0002.

37. Davis $R$, Peters DH, McTavish D. Valproic acid: A reappraisal of its pharmacological properties and clinical efficacy in epilepsy. Drugs. 1994;47(2):332-72

38. Grant SM, Heel RC. Vigabatrin. A review of its pharmacodynamic and pharmacokinetic properties, and therapeutic potential in epilepsy and disorders of motor control. Drugs. 1991;41(6):889-926.

39. Shelp BJ, Bown AW, McLean MD. Metabolism and functions of gamma-aminobutyric acid. Trends Plant Sci. 1999;4(11):446-52.

40. Small supernumerary marker chromosomes (sSMC) [database on the Internet]. Available from: http://ssmc-tl.com/chromosome-15.html\#sei.

41. Caspersson T, Zech L, Johansson C, Modest EJ. Identification of human chromosomes by DNA-binding fluorescent agents. Chromosoma. 1970;30(2):215-27.

42. Pinkel D, Landegent J, Collins C, Fuscoe J, Segraves R, Lucas J, et al. Fluorescence in situ hybridization with human chromosome-specific libraries: detection of trisomy 21 and translocations of chromosome 4. Proc Natl Acad Sci U S A. 1988;85(23):9138-42.

43. Glatt $K$, Sinnett D, Lalande M. The human gamma-aminobutyric acid receptor subunit beta 3 and alpha 5 gene cluster in chromosome 15q11-q13 is rich in highly polymorphic (CA)n repeats. Genomics. 1994;19(1):157-60. doi:10.1006/geno.1994.1027

44. Gyapay G, Morissette J, Vignal A, Dib C, Fizames C, Millasseau P, et al. The 1993-94 Genethon human genetic linkage map. Nat Genet. 1994;7(2 Spec No):246-339. doi:10.1038/ng0694supp-246.

45. Kallioniemi A, Kallioniemi OP, Sudar D, Rutovitz D, Gray JW, Waldman F, et al. Comparative genomic hybridization for molecular cytogenetic analysis of solid tumors. Science. 1992;258(5083):818-21.

\section{Submit your next manuscript to BioMed Central and take full advantage of:}

- Convenient online submission

- Thorough peer review

- No space constraints or color figure charges

- Immediate publication on acceptance

- Inclusion in PubMed, CAS, Scopus and Google Scholar

- Research which is freely available for redistribution

Submit your manuscript at www.biomedcentral.com/submit 